\title{
O SERVIÇO SOCIAL NO NASF: UM RELATO DE REALIDADE
}

\author{
Roberta Conrad ${ }^{1}$ \\ Suzana Matheus Pereira ${ }^{2}$ \\ Tamara Alexandra Arias Schutel ${ }^{3}$
}

RESUMO: Introdução: Considerando o conceito ampliado de saúde e seus determinantes sociais, este artigo se apresenta como fonte exemplificativa da importância da inserção do assistente social nos NASF, através do trabalho multiprofissional e intersetorial. Relato de caso: Trata-se se uma idosa diabética residente em um bairro de Florianópolis, aposentada e estava com complicações decorrentes de uma ferida aberta devido a diabetes e por isso com muita dificuldade de caminhar. Sua filha e sua neta de ro anos moram com ela. Uma trabalha em período integral e a outra cuida da avó à tarde. A demanda trazida pela família foi a respeito de como colocar a idosa em uma Instituição de Longa Permanência para Idosos (ILPI) e este artigo trata das ações desencadeadas pelo serviço social do NASF na solução das questões relacionadas à qualidade de vida da idosa. Conclusão: Através desse artigo é visto a importância da inserção do assistente social no NASF, trazendo profundas contribuições para as equipes de saúde da família, uma vez que se coloca como o principal articulador entre as políticas públicas, propiciando estratégias de diálogo entre equipe e comunidade, trabalhando na garantia de direitos da população.

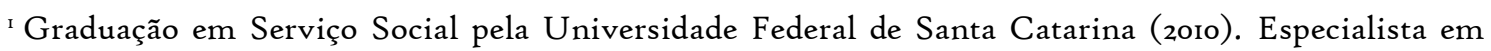
Saúde da Família (2015-2017) pelo Programa de Residência Multiprofissional em Saúde da Família, UDESC, pela Secretaria Municipal de Saúde de Florianópolis. Tem experiência na área de Serviço Social, com ênfase em Serviço Social Aplicado. Qualificaçãoem RH pela ABRH Associação Brasileira de Recursos Humanos. Tutora no curso Prevenção ao uso de Drogas (EADUFSC) para conselheiros municipais. Atua na Prefeitura de Palhoça na Proteção Social Básica (CRAS) e COMDIM (Conselho Municipal dos direitos da Mulher) e também no setor de Benefícios Sóciossistenciais e atualmente sou assistente social da Prefeitura Municipal de São José. E-mail: betacrd@hotmail.com.

${ }^{2}$ Doutora em Ciências do Desporto pela Universidade do Porto (2009). Possui mestrado em Ciências do Movimento Humano pela Universidade do Estado de Santa Catarina (2001). Atualmente é professora adjunta da Universidade do Estado de Santa Catarina e desenvolve projetos de pesquisa em Fisioterapia, Biomecânica, Natação, Iatismo, Pilates, Hidroginástica e Exercícios Aquáticos no Laboratório de Pesquisas em Biomecânica Aquática do Centro de Ciências da Saúde e Desporto da UDESC.

3 graduação em Serviço Social pela Universidade Federal de Santa Catarina (2012). Pós-graduação em Saúde da Família modalidade Residência (2015). Atualmente é assistente social no Núcleo de Apoio à Saúde da Família no Município de São José. Tem experiência na área de Serviço Social, com ênfase em Saúde, Saúde Mental e uso abuso de crack e outras drogas.
} 
Palavras- chaves: Serviço social. saúde da família. ação intersetorial. Equipe interdisciplinar de saúde.

ABSTRACT: Introduction: Taking into consideration the expanded concept of health and its social determinants, this article presents an exemplary source of the importance of the social worker insertion in the Family Health Support Center (NASF) through multiprofessional and intersectoral work. Case Report: this article, through a case study at a Health Center in the city of Florianópolis-SC, aims to valorize the role of this professional in NASFs, demonstrating its primordiality, since it has the capacity to undestand the human as whole. In this way, it will report the tools to assure the right to health and promoting citizenship of the subject. Conclusion: Therefore, the NASF social worker brings deep contributions to the family health teams, since it is the main articulator between public policies, providing strategies for dialogue between health staff and community, working to assure the rights of the population.

Keywords: social work. family health. intersectoral action. patient care team.

\section{INTRODUÇÃO}

A Estratégia de Saúde da Família (ESF) é a vertente brasileira da Atenção Primária à Saúde (APS), que se caracteriza como a porta de entrada prioritária do

Sistema Único de Saúde (SUS), constitucionalmente fundado com base na equidade do cuidado hierarquizado e regionalizado. A ESF vem provocando um importante movimento de reorientação do modelo de atenção à sociedade, onde a sua principal finalidade é reorganizar a prática da atenção à saúde em novas bases e substituir o modelo tradicional, levando o cuidado para mais perto das famílias e, com isso, melhorar a qualidade de vida da população.

A metodologia de trabalho das equipes de Saúde da Família (SF) é o elemento chave para a busca permanente de comunicação e troca de experiências e conhecimentos entre os integrantes da equipe e destes com a comunidade. As equipes de SF são compostas por no mínimo um médico de família, um enfermeiro, um auxiliar de enfermagem e agentes comunitários de saúde. Pode ser ampliada com a equipe de Saúde Bucal, na qual estão presentes: dentista, auxiliar em saúde bucal e técnico em saúde bucal. 
A equipe de atenção básica está alocada geralmente em um centro de saúde que é responsável pelo cuidado da população de um determinado território. A territorialização é um instrumento de avaliação da Estratégia Saúde da Família (ESF) que visa à compreensão atual do processo saúde doença, apontando que as variáveis biológicas, psíquicas e sociais remetem a necessidade de ações que possa compreender e intervir nos problemas que afetam um território. Segundo Mendes ${ }^{\mathrm{I}}$ o território é um espaço em permanente construção e reconstrução. É a concepção de território processo que além de um território solo é território econômico, político, cultural e epidemiológico, configurando uma realidade de saúde sempre em movimento e nunca pronta.

$\mathrm{Na}$ perspectiva de apoiar à ESF na rede de serviços e ampliar a abrangência, resolutividade, territorialização, regionalização, bem como a ampliação das ações na APS, o Ministério da Saúde (MS) criou os Núcleos de Apoio à Saúde da Família (NASF), mediante a Portaria GM no $154^{2}$. Segundo esta portaria o NASF é composto por profissionais de diversas áreas que atuam de forma integrada com as Equipes da Atenção Básica (AB).

Atualmente a legislação prevê três tipos de NASF, porém, devido ao escopo deste artigo será apresentado apenas o NASF i que é composto por no mínimo cinco profissionais com formação universitária, entre os seguintes: psicólogo, assistente social, farmacêutico, fisioterapeuta, fonoaudiólogo, ginecologista, profissional da educação física, médico homeopata, nutricionista, médico acupunturista, pediatra, psiquiatra e terapeuta ocupacional. Cada NASF deve estar vinculado a um mínimo de oito e máximo de vinte equipes de ESF².

Assim, o NASF constitui uma rede de cuidados através da relação articulada com as equipes de saúde da família, com a pretensão de dar suporte para que os serviços de saúde sejam ofertados de forma integral e ampla e para isso dispõe de ferramentas estratégicas, tais como: apoio matricial, clínica ampliada, projeto terapêutico singular (PTS) e projeto de saúde no território (PST) 3 descritos abaixo: 
- Apoio Matricial: se complementa com processos de trabalho em equipes de referência responsável por produzir ação clínica direta com os usuários, caracterizada pela ação técnico-pedagógica, que produz apoio educativo com e para a equipe.

- Clínica Ampliada: a proposta de Clínica Ampliada se direciona a todos os profissionais que fazem clínica, ou seja, os profissionais de saúde na sua prática de atenção aos usuários. Toda profissão faz um recorte, um destaque e informações, cada uma de acordo com seu núcleo profissional. Ampliar a clínica significa ajustar os recortes teóricos de cada profissão às necessidades dos usuários. A discussão em equipe de casos clínicos, principalmente se mais complexos, é um recurso clínico e gerencial muito importante. Este é um espaço privilegiado para o apoio matricial e, portanto, para o trabalho dos profissionais do NASF.

- Projeto Terapêutico Singular - PTS: constitui-se em um conjunto de propostas de condutas terapêuticas articuladas, direcionadas a um sujeito individual ou coletivo, realizada por uma equipe interdisciplinar, com apoio matricial se necessário. Geralmente é dedicado a situações mais complexas. É uma variação da discussão de "caso clínico". Ele representa um momento em que toda a equipe compartilha opiniões e saberes na tentativa de ajudar a entender o sujeito com alguma demanda de cuidado em saúde e, consequentemente, para definição de propostas de ações.

- Projeto Saúde no Território: se desenvolve através de ações efetivas na produção da saúde em um território, articulando os serviços de saúde com outros serviços e políticas sociais, de forma a investir na qualidade de vida e na autonomia dos sujeitos.

O NASF busca operar numa lógica de corresponsabilização e gestão integrada na atenção à saúde, por meio de atendimentos e projetos terapêuticos que envolvam usuários e equipe, além de considerar a priori a singularidade dos sujeitos assistidos. O trabalho no NASF tem o propósito de resgatar o cuidado contínuo que envolve desde o processo interativo entre quem cuida e é cuidado até o estabelecimento de parcerias intersetoriais ${ }^{4}$, tais como dispositivos da assistência social, habitação, infraestrutura, judiciário e demais que se fizerem necessários. 
A atuação do Serviço Social na saúde iniciou-se somente em meados de 1980 quando se consolida o projeto ético político da profissão e a política de saúde, traçando em 1990, no projeto da reforma sanitária, as seguintes questões a serem trabalhadas pelo Serviço Social:

[...] democratização do acesso às unidades e aos serviços de saúde; estratégias de aproximação das unidades de saúde com a realidade; trabalho interdisciplinar; ênfase nas abordagens grupais; acesso democrático às informações e estímulo à participação populars.

A inclusão do serviço social nos NASF está em consonância com os princípios éticos e políticos da profissão e do projeto da reforma sanitária. Esse profissional é fundamental para o que prevê a Portaria n. $154^{2}$, onde o serviço social desenvolve ações privilegiadas de promoção da cidadania e estratégias que fortaleçam as redes de suporte social, propiciando a integração entre os serviços de saúde e outros equipamentos públicos no território adscrito, contribuindo para o desenvolvimento de ações intersetoriais que visem ao fortalecimento da cidadania.

Diante desse contexto, compreende-se que a população necessita conhecer seus direitos e saber que possuem autonomia para efetivação destes. Este é um importante papel do serviço social, pois é através do conhecimento que a população pode se organizar e promover mudanças.

No documento BRASIL (2010) ${ }^{6}$ estão estabelecidos alguns objetivos para o Serviço Social no NASF:

Incentivar e contribuir no processo de fortalecimento da autonomia e da organização pessoal do usuário; 3. Apoiar os usuários na construção e ressignificação de seu projeto de vida; 4. Criar espaços grupais que possibilitem a construção de relações humanizadoras e socializadoras por meio de trocas de experiências e construção de rede de apoio; 5. Desenvolver ações integradas com os profissionais da equipe correlacionados com a área de atuação em atenção à saúde e demais políticas públicas; 6. Socializar informações nas equipes e participar de discussão de situações vivenciadas por usuários e/ou familiares com as demais categorias profissionais, valorizando as ações desenvolvidas por eles; 7. Promover a integração dos demais membros da equipe de trabalho; 8. Produzir conhecimento sobre a população atendida na área da saúde, processo de pesquisa e a especificidade do serviço social; 9. Participar da elaboração conceitual/metodológica para apoiar as práticas educativoparticipativas desenvolvidas pela equipe de trabalho, com usuários e população atendida; io. Construir coletivamente e de forma participativa entre a equipe de saúde, segmentos organizados da comunidade, usuários e demais sujeitos sociais populares envolvidos a organização do trabalho comunitário. II. Incentivar a participação dos usuários nos fóruns de 
discussão e deliberação, tais como: Conselhos Locais de Saúde, Conselho Distrital de Saúde, Conselhos de Assistência Social, Conselho de Direitos da Criança e do Adolescente, Conselhos do Idoso e demais Conselhos de direitos, Reuniões da Comunidade, e outros.

Para explicitar a atuação do Serviço Social no NASF será descrito a seguir um relato de experiência embasada em uma situação atendida por uma ESF juntamente com o NASF do Município de Florianópolis, apontando a importância da articulação intersetorial e o trabalho multiprofissional, através de mecanismos capazes de garantir o direito à saúde e promover a cidadania do sujeito.

A fim de manter o sigilo dos sujeitos envolvidos, estes serão identificados por nomes fictícios.

\section{RELATO DE CASO}

Devido à complexidade da situação foi escolhida a família de Norma (7o anos), para retratar a atuação da assistente social e as ações interdisciplinares e intersetoriais desenvolvidas pela equipe. A família era acompanhada pela ESF, mas ainda não tinha sido atendida pelo Serviço Social do NASF. Quem buscou o primeiro atendimento da assistente social residente foi Carla, que mora com a sua mãe Norma e sua filha Amanda (Io anos), conforme Figura I.

Neste primeiro contato que aconteceu no final do mês de junho de 2015, Carla relatou que sua mãe Norma é aposentada e está com complicações decorrentes de uma ferida aberta devido a diabetes e por isso com muita dificuldade de deambular, fazendo uso de cadeira de rodas para se locomover. Norma faz uso de insulina diariamente, além de outras medicações de uso contínuo.

Sua filha Carla trabalha em período integral e não consegue prestar assistência para a mãe que durante à tarde fica "aos cuidados" da neta Amanda. Neste primeiro atendimento a demanda trazida pela família foi a respeito de como inserir Norma em uma Instituição de Longa Permanência para Idosos (ILPI). Então, foi orientado a respeito da importância dos cuidados com a idosa e com a criança e também foi agendado uma Visita Domiciliar (VD) para conhecer a realidade social em que a família está inserida bem como a dinâmica entre seus membros. 
Antes da VD foi realizado o matriciamento com a enfermeira da área de abrangência em que reside a família e foi decidido realizar a vista domiciliar juntamente com a assistente social, enfermeira e a Agente Comunitária de Saúde (ACS).

No dia 30 de junho, ao chegarem à casa estavam somente Norma e a criança Amanda. Norma relata que além de Carla tem mais dois filhos Davi e Rafael, um residindo num bairro próximo e o outro morando em outro estado. Davi, ajuda nas demandas médicas, levando-a para consultas, compras de medicamentos e exames. Com Rafael mantém contatos esporádicos por telefone. Já com Carla descreve relações conflituosas, constantes brigas e trocas de ofensas.

Nesta mesma ocasião Norma afirma que o sustento da casa se dá através da sua aposentadoria de um salário-mínimo, juntamente com a renda do trabalho de Carla, que também não é muito, porém, não cita valores. Amanda frequenta o colégio de manhã e no período vespertino auxilia Norma nos cuidados com a casa e saúde.

Durante a VD as profissionais notaram grande falta de cuidado em relação a higiene da casa, o que poderia estar piorando a situação da ferida na perna de Norma. $\mathrm{Na}$ geladeira estavam diversas listas com tarefas a serem desenvolvidas pela criança, tal como afazeres domésticos, cuidados com Norma, administração de medicamentos, etc. Considerando que Carla trabalha o dia todo em um escritório de contabilidade e na casa permanecem apenas a idosa e a criança, é evidente que as duas não consigam proporcionar um ambiente salubre e digno de ser habitado.

Em contato com a rede secundária de cuidados, vizinhos relataram que por diversas vezes tiveram que socorrer a idosa devido a quedas e outros perigos iminentes, levando-a para hospitais, Unidade de Pronto Atendimento (UPA) e Posto de Saúde. Também informaram que várias vezes tentaram contato com algum dos filhos após acionarem o Serviço de Atendimento Móvel de Urgência (SAMU), mas nunca conseguiam contato. Assim, tanto a idosa quanto a criança ficavam sem o cuidado necessário. 
Após a realização da VD foi dado o retorno, através da enfermeira da ESF, via contato telefônico com a filha Carla, para algumas orientações necessárias que poderiam vir a mudar tal realidade situacional da família, e que a ESF entraria em contato também com os outros filhos de Norma para traçar um Projeto Terapêutico.

Em 20 de julho foi realizado um novo matriciamento para reflexão e construção do plano de intervenção, visto que em outra VD, desta vez com o médico da área, as condições de saúde e da residência estavam mais insalubres. A equipe considerou pertinente agendar uma reunião familiar com todos os filhos da paciente. Através do contato com a filha Carla e o filho Davi, que residem em Florianópolis, foi agendada uma reunião para o dia 27 de julho de 2015 .

Os filhos não compareceram a reunião previamente agendada e também não justificaram sua ausência. Através do contato telefônico com Carla neste mesmo dia, a mesma afirmou não ter sido liberada do trabalho, já com o filho Davi, a equipe não conseguiu contato. No dia seguinte houve nova tentativa de reunião familiar com a equipe da ESF e NASF, todavia, sem sucesso.

Importante ressaltar que na semana posterior da reunião agendada, a filha Carla compareceu ao Centro de Saúde, muito aflita, alegando que recebera uma intimação do juiz devido a denúncias de maus tratos contra Norma. Durante o atendimento a assistente social lembrou que a reunião familiar havia sido agendada justamente para criar estratégias de ação e que também foi orientada a comparecer no dia e hora marcada pelo Juiz.

Esgotadas todas as possibilidades de intervenções no escopo da ESF e NASF a equipe concluiu por encaminhar relatórios situacionais para o Serviço de Proteção Especial para Pessoas com Deficiência, Idosas e suas Famílias (SEPREDI) de responsabilidade da Proteção Social Especial de Média Complexidade da Assistência Social, e para o Conselho Tutelar, por também se tratar de violação de direitos da criança Amanda.

Após acionar outras instituições competentes para intervir na situação relatada acima, Norma foi acolhida em uma ILPI (Instituição de Longa Permanência) próximo de sua residência e pôde continuar sendo acompanhada pela 
assistente social residente do NASF. Apresentou uma melhora significativa das suas condições de saúde e dessa forma também maior autonomia. Pelo fato da ILPI ficar próximo de sua residência os laços familiares foram estreitados. Já a Amanda foi inserida no Centro de Convivência e Fortalecimento de Vínculos de responsabilidade da Proteção Social Básica, ofertado pelo CRAS (Centro de Referência em Assistência Social).

\section{DISCUSSÃO}

Há muito tempo, o conceito de saúde era sinônimo de ausência de doenças físicas e mentais e, por isso, os serviços de saúde privilegiaram na sua organização e atendimento à atenção médica curativa em detrimento das ações de prevenção e promoção da saúde.

Mais recentemente a Organização Mundial de Saúde (OMS) define que "saúde é um estado de completo bem-estar físico, mental e social e não consiste apenas na ausência de doença e enfermidade"7. Essa definição explicita a complexidade do tema e a reflexão mais acurada sobre seu significado leva a considerar a necessidade de ações intersetoriais e interdisciplinares no sentido de criar melhores condições de vida para a população.

No processo de trabalho no NASF, o assistente social tem vários objetivos, como: desenvolver ações que possibilitem garantir a escuta e acolhida do usuário de forma qualificada; incentivar a autonomia do usuário e sua participação; fazer pesquisas sobre a população de sua área de atuação ${ }^{8}$. Conforme explicitado no relato de caso, na organização do seu processo de trabalho, o assistente social segue algumas estratégias metodológicas que vão ser utilizadas de acordo com cada demanda. São estas: escuta qualificada, abordagem grupal, familiar, individual e de rede social; visita domiciliar; grupos educativos e/ou de convivência; visitas institucionais; estudo social; aperfeiçoamento, formação e produção de conhecimentos, diferenciando-se de outras profissões no tocante à visão crítica e de totalidade da realidade estudada.

Dessa forma, o trabalho intersetorial supõe não apenas o contato ou o trabalho simultâneo entre os atores envolvidos, mas também a busca por resultados, 
necessitando de diálogo, envolvimento, interface, conexão, participação, e isso supõe articulação em rede.

Os municípios de grande porte, como Florianópolis, lócus deste estudo de caso, contam com maior número de dispositivos para articulação intersetorial, seja da esfera pública, privada e terceiro setor. A interlocução com espaços como os Centros de Referência da Assistência Social (CRAS), Centro de Referência Especializado da Assistência Social (CREAS), Conselho Tutelar, hospitais, casas-lares, judiciário, defensoria pública, além de mobilização popular e controle social, entre outras, é peça central para a garantia de direitos que como afirma Mioto9 "os direitos são entendidos como caminhos para a concretização da cidadania por meio de políticas sociais orientadas para o atendimento das necessidades humanas, e o Estado reconhecido como instância responsável por essa garantia e atenção”.

Nesta experiência é percebido como a articulação intersetorial realizada pela equipe do NASF foi o ponto central para a resolutividade das demandas expostas. Uma vez que, além de dialogar com o Conselho Tutelar, também foram acionadas desde a política de assistência social nos seus três níveis de proteção, ao articular com

o Centro de Convivência e Fortalecimento de Vínculos pertencente a proteção social básica, quando acionado o SEPREDI, que é serviço da Proteção Social Especial de Média Complexidade, chegando até mesmo a alta complexidade ao precisar da" proteção integral ${ }^{\mathrm{10} "}$ da ILPI.

Assim sendo, o apoio matricial do NASF a ESF foi primordial no bom desenvolvimento e atendimento da paciente e seus familiares, pois propiciou trocas, educação continuada, diálogos e a construção do PTS neste espaço. Segundo Arona ${ }^{\mathrm{II}}$

O apoio Matricial é um arranjo de gestão que possibilita a organização das ações de saúde da especialidade na atenção básica e amplia o acesso nas equipes de saúde da família, favorecendo a construção de novos arranjos, onde, com uma equipe mais qualificada, é possível pensar cada situação dentro de sua especificidade, sob diferentes olhares.

As práticas do Serviço social no NASF possibilitam aos profissionais a definição de suas competências, abrangendo-as como parte de conjunto de práticas e saberes mais amplos que se complementam na interlocução e na vivência cotidiana com a população e com as diversas categorias profissionais, para a efetivação de um modelo de atuação promotor de saúde e cidadania. 
Ressalta-se que é recomendado que as ações devam ser desenvolvidas de forma interdisciplinar e integrada com os demais profissionais das equipes, partindo de um conhecimento aprofundado do território de abrangência, de seu perfil epidemiológico, do mapeamento das situações e áreas de maior risco, sendo o/a assistente social do NASF responsável pelas ações que promovem o desenvolvimento de toda comunidade, fortalecendo os espaços sociais, comunitários e locais em geral, percebidos através de conselhos e conferências.

Portanto, o assistente social na saúde não atua na perspectiva de apenas uma demanda, como por exemplo, uma dor de dente requer um dentista. Sua especificidade está em atuar numa ampla abrangência das necessidades humanas de uma determinada classe social, ou seja: o/a assistente social deve intervir nas diversas expressões da questão social no âmbito da saúde e para isso é fundamental uma intervenção crítica e reflexiva da realidade social, conhecendo os recursos e equipamentos sociais existentes.

Contudo, há ainda alguns desafios para o processo de trabalho do assistente social no NASF, como a precarização das redes de apoio, falta de compreensão de alguns profissionais na saúde do que é o Serviço Social, investimento do poder público nos serviços e servidores, falta de capacitação continuada.

Diante desse estudo de caso é visto que o trabalho multiprofissional e a interdisciplinaridade tem suma importância na Atenção Primária à Saúde, e que o Serviço Social ao inserir-se na equipe multiprofissional de atenção primária à saúde, protagoniza a construção de ações coletivas que ultrapassam as práticas meramente clínicas, estimulando as equipes no fortalecimento de ações que visam o alcance da saúde individual e coletiva e as suas determinações, as quais regem o acesso aos bens e serviços indispensáveis à garantia dos direitos sociais, sobretudo em situações cujos determinantes advêm de condições precárias de vida.

Portanto, envolve-se interdisciplinarmente na resolução dos problemas de saúde construindo estratégias de ação direcionadas a indivíduos e famílias, articulando-as ao contexto social ao construir redes e ao estimular a inscrição na esfera pública, das demandas que devem ser debatidas coletivamente em prol da garantia de direitos. 


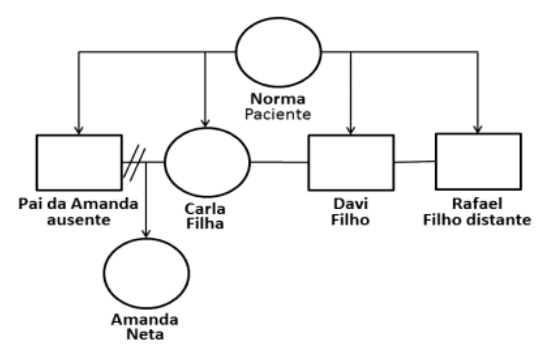

Figurar: Genograma do caso atendido pelo Serviço Social do NASF.

\section{REFERÊNCIAS}

I. MENDES E. V. 1993b. A construção social da Vigilância à Saúde do Distrito Sanitário. Série Desenvolvimento de Serviços de Saúde, n. Io,: 7-19, Brasília, OPS.

2. BRASIL, Ministério da Saúde. Portaria GM No, 154, de 24 de Janeiro de 2008. Cria os Núcleos de Apoio à Saúde da Família - NASF.

3. Figueiredo, E. N. Módulo Político Gestor, Estratégia Saúde da Família e Núcleo de Apoio à Saúde da Família: diretrizes e fundamentos. Disponível em: http://www.unasus.unifesp.br/biblioteca_virtual/esf/r/modulo_politico_gestor/Unidade_5. pdf

4. SOUZA, F. L. D.; CHACUR, E. P.; RABELO, M. R. G.; SILVA, L. A. M.; VILLELA, W. V. Implantação do Núcleo de Apoio à Saúde da Família: percepção do usuário. Saúde em Debate • Rio de Janeiro, v. 37, n. 97, p. 233-240, abr./jun. 2013.

5. CFESS. Conselho Federal de Serviço Social. GT EDUCAÇÃO. Subsídios para o Debate sobre Serviço Social na Educação. Brasília: CFESS, 2oı, p. 24.

6. BRASIL, Ministério da Saúde. Secretaria Executiva. Sistema Único de Saúde (SUS): princípios e conquistas. Brasília: Ministério da Saúde, 2010.

7. OMS. Organização Mundial de Saúde. Atas oficiais, nº̂2, p.ıoo.

8. BRASIL. Ministério da Saúde. Diretrizes do NASF: Núcleo de Apoio Saúde da Família. Brasília: Cadernos de Atenção Básica. n. 27, Série A. Normas e Manuais Técnicos. Brasília: Ministério da Saúde, 2010.

9. MIOTO, R. C. T. Família, trabalho com famílias e Serviço Social. In: Serv. Soc. Ver, Londrina, V.12, n.2, p.163-176, 2010. 
Io. BRASIL. Ministério do Desenvolvimento Social e Combate à Fome - Secretaria Nacional de Assistência Social. Política Nacional de Assistência Social PNAS/2004; Norma Operacional Básica - NOB/Suas. Brasília:, 2005.

II. Implantação do Matriciamento nos Serviços de Saúde de Capivari. Disponível em: http://www.revistas.usp.br/sausoc/article/viewFile/29526/31391 